\title{
A INSTITUIÇÃO ESCOLAR MEDIANTE OS DESAFIOS NA IDENTIFICAÇÃO DE VULNERABILIDADE INFANTIL EM TEMPOS DE PANDEMIA.
}

Semana Online Científica de Educação, 1a edição, de 25/10/2021 a 27/10/2021

ISBN dos Anais: 978-65-81152-18-5

SILVA; Sonai Maria da ${ }^{1}$

\section{RESUMO}

INTRODUÇÃO O presente resumo traz a temática referente aos desafios a serem enfrentados por instituições escolares na identificação de vulnerabilidade infanto-juvenil em tempos de pandemia com base em dados de estudo recente do Fundo das Nações Unidas para a Infância UNICEF sobre este tema. OBJETIVO: Analisar com base nas discussões levantadas até o momento sobre os desafios para a instituição escolar na identificação de vulnerabilidade infanto-juvenil em tempos de pandemia. METODOLOGIA Foi realizada pesquisa bibliográfica qualitativa tendo como foco de estudo e análise a vulnerabilidade infanto-juvenil em temppos de pandemia e o desafio para a escola em detectar estes casos no presente momento. RESULTADOS E DISCUSSÃO Segundo pesquisa realizada pela UNICEF, $27 \%$ dos respondentes relataram que adolescentes apresentaram insônia ou excesso de sono; $29 \%$ tiveram alteração no apetite e $28 \%$ tiveram diminuição no interesse por atividades rotineiras. No total, 54\% das famílias relataram que algum adolescente na família apresentou algum sintoma relacionado à saúde mental. Estes resultados mostram como a mudança de rotina com o afastametno presencial da escola e o confinamento afetou a saúde mental de crianças e adolescentes. CONCLUSÃO A qualidade do ensino e a segurança dos alunos neste momento de retorno as aulas somente será possível se houver compreensão, cooperação e espírito de equipe. Os casos identificados como situações de vulnerabilidade infanto-juvenil exigem medidas de proteção como prevê o Estatuto da Criança e do Adolescente(ECA), Lei 8.069/90 que determina as crianças e adolescentes como "sujeitos de direito". Além disso é importante haver uma rede de proteção entre as instituições escola, conselho tutelar, vara da infância, assistência social e serviços de saúde para uma melhor avaliação, garantindo tratamento adequado e medidas de proteção para a criança e adolescente.

PALAVRAS-CHAVE: escola - vulnerabilidade infanto-juvenil - pandemia 